\title{
Smart Building Hybrid Ventilation System under Wireless Sensor Network Environment
}

\author{
Yun-Wu Wu, ${ }^{1}$ Jin-Lian Lee, ${ }^{1}$ Wei-Chung Kuo, ${ }^{2 *}$ and Ding-Chin $\mathrm{Chou}^{3}$ \\ ${ }^{1}$ Department of Architecture, China University of Technology, \\ No. 56, Sec. 3, Xinglong Rd., Wenshan Dist., Taipei City 116, Taiwan (R.O.C.) \\ ${ }^{2}$ Doctoral Program in Design, College of Design, National Taipei University of Technology, \\ No. 1, Sec. 3, Zhongxiao E. Rd., Da'an Dist., Taipei City 106, Taiwan (R.O.C.) \\ ${ }^{3}$ Department of Architecture, National Taipei University of Technology, \\ No. 1, Sec. 3, Zhongxiao E. Rd., Da'an Dist., Taipei City 106, Taiwan (R.O.C.)
}

(Received December 4, 2019; accepted April 24, 2020)

Keywords: green building, Internet of Things, comfort level, indoor temperature regulation

Natural building ventilation is an effective method for maintaining comfortable and healthy indoor environments. This study aims to develop a novel smart building hybrid ventilation system capable of tracking wind direction using wireless control technologies and sensory capabilities. Natural and mechanical ventilation components are integrated to create a highly efficient and healthy ventilation system for a building. With this system, wind speed and direction are measured using a windmill anemometer, and this information is relayed to the control system. The control system uses this information to modify the openings of the adjustable rooftop developed in this study toward the direction of the wind using a set of interlinked devices. This guides fresh airflow indoors, improving the comfort of indoor environments through the circulation of airflow. This is expected to reduce the energy consumption of air-conditioning systems.

\section{Introduction}

Natural building ventilation is an effective method to maintain comfortable and healthy indoor environments. However, creating naturally ventilated building designs requires a thorough understanding of a building's intrinsic structure and ventilation methods. ${ }^{(1)}$ A building's rate of ventilation is strongly dependent on its aspect ratio and the position of its external openings with respect to wind direction. ${ }^{(2)}$ Consequently, longer buildings tend to have lower ventilation rates. The performance of a building's ventilation may be assessed using five indices: flow rate, pollutant removal, heat discharge, exposure, and air distribution. ${ }^{(3)}$

The natural ventilation of a building refers to the design of ventilation structures for passive wind guidance. As the flow of natural building ventilation is generated by the difference in temperature between the interior space and the external environment, this mode of ventilation uses only natural wind and heat energy, and results from the solar heating of the building. Thermal buoyancy increases the area of ventilation and drives greater levels of flow, increasing

*Corresponding author: e-mail: t105859012@ntut.edu.tw

https://doi.org/10.18494/SAM.2020.2729 
the convection of gases. Although these resources are freely available, they are very difficult to control. $^{(4,5)}$ Some of the factors that affect natural building ventilation include the time of day, season, temperature, humidity, external wind speed, orientation, building position, openings in the building, the configuration of the building site, and the number of floors. In addition, urban climate patterns and artificial environmental factors also impact on ventilation efficacy. As such, attention to detail is necessary when implementing natural wind guidance in different buildings. ${ }^{(6-8)}$

In energy-saving designs using natural ventilation, the main advantage of using wind towers is their passive energy saving capability and their ability to be installed externally, that is, on top of buildings. Wind towers reduce the electric energy required for indoor comfort during the warmer months of the year, particularly around peak periods. During the daytime, hot air from outdoors is guided into the wind tower via its opening. By setting up an air-intake opening and an exhaust opening at different ends, cooled air is carried inside. The opposite pattern occurs at night. Wind towers are most suitable for environments with large temperature differences: high temperatures in the day and low temperatures at night. After the heat exchange during the day, the temperature of the wind tower becomes higher than nighttime temperatures. Because of thermal buoyancy, the air inside the wind tower starts to rise after the tower's high-temperature surfaces heat it up. This promotes indoor air flow in the opposite direction. Some researchers have also suggested using transparent materials in building wind towers as a way of making better use of natural lighting. ${ }^{(9)}$

A building's ventilation is central to the comfort and health of its indoor users, and the use of natural methods helps reduce energy consumption. ${ }^{(10,11)}$ In this regard, nighttime airflow emerges as the most effective form of natural ventilation ${ }^{(12,13)}$ and is superior to daytime ventilation. However, daytime ventilation is in turn better than all-day ventilation, with the absence of ventilation being the least energy-efficient case. ${ }^{(14)}$ The effectiveness of nighttime natural ventilation is not affected by shading effects or windscreen panels of adjacent buildings. ${ }^{(15)}$ Under hot and humid conditions, nighttime ventilation is the most effective strategy for reducing indoor temperatures when combined with low-heat-capacity buildings. Under hot and dry conditions, the use of high-heat-capacity buildings in combination with natural ventilation will yield the lowest indoor temperatures. ${ }^{(16)}$ As a whole, the appropriate use of nighttime ventilation will reduce daytime energy consumption and air-conditioning loads, thereby saving energy.

The purpose of life-cycle cost (LCC) optimization methods is to analyze the viability of energy-saving techniques during the early stages of building design. The need to save energy while keeping costs at a reasonable level has prompted us to construct a unified structure for energy simulations using Energy Plus and cost optimization, and we proposed a procedure for implementing energy-saving optimizations and energy-saving designs. ${ }^{(17)}$ The use of Energy Plus airflow network modeling and computational fluid dynamics (CFD) calculations will allow multidirectional ventilation performance analyses and provide information and predictions related to the performance of natural ventilation. Furthermore, the models used in ventilation performance predictions may be further improved through the input of experimental data. ${ }^{(18,19)}$

The development of the Internet and information technologies has led to the development of novel ventilation schemes. In addition to the dictates of the ventilation system and building 
structure relationships, such schemes create intelligent ventilation systems by emphasizing the use of automated control techniques that use sensor devices and the Internet of Things (IoT). ${ }^{(20,21)}$ The development of these intelligent systems mainly proceeds in two directions. The first is remote control, ${ }^{(22)}$ in which wireless communications and information techniques are used to develop automatable and remote-controllable systems. The second is the design of personalized systems. ${ }^{(23,24)}$ Here, user data is collected for operational analysis and used to understand user requirements and construct a service system that will satisfy the personalized needs of each user.

In addition to previously described remote-control and personalized-adjustment-ofventilation systems, these new IoT techniques also facilitate interactive techniques that rely on machine-to-machine communication. ${ }^{(25)}$ With these interactive techniques, operational models are constructed through the collection of sensor data, then used to control and manage machines in a fully autonomous manner. This facilitates the control of machines through the IoT and imbues control systems with the capacity for sensory perception. This will ultimately lead to the construction of fully autonomous intelligent systems. ${ }^{(26)}$

The literature demonstrates that research on the natural ventilation of buildings generally tends toward passive approaches. However, the primary considerations for wind-powered ventilation are the external wind speed and direction, building openings, and the building configuration. Our understanding of environmental control via architectural means is becoming increasingly comprehensive owing to the progress made in various studies, and external ventilation methods should be given serious consideration in future developments. ${ }^{(27)}$ Cross-disciplinary applications and innovative fabrication methods are necessary for solving the ventilation problem, and objects with composite functions will become increasingly ubiquitous in the future. High-tech products are particularly necessary to improve building-related applications as they play a key role in extending the life cycle and service life of buildings. This in turn helps reduce energy consumption and greenhouse emissions. ${ }^{(28)}$

In this study, we used IoT techniques and sensor devices to develop a wind-tracking architectural design based on a previously described intelligent machine-to-machine communication architecture. ${ }^{(29,30)}$ This technology was also implemented in the form of an interactive model used to simulate actual usage scenarios. Specifically, we developed a windtracking ventilation structure that maintains indoor air quality and comfort through the removal of hot and stagnant air. The structure was integrated with a wireless sensor network for the monitoring and control of indoor environments. As such, we constructed a wind-tracking ventilation system that will save energy and create healthy indoor environments while also being equipped with IoT technologies.

\section{Design of Wind-tracking Ventilation System}

\subsection{System overview}

In this study, we designed a ventilation system that actively controls natural ventilation through the use of adjustable roof skylights and wireless sensor networks. In most ventilation 
models, the building ventilation rate is calculated using the openings. Although both the dominant processes in ventilation and the effects of internal obstacles on ventilation rates remain open for debate, it is generally accepted that the configuration of the internal environment in each room affects the indoor temperature, humidity, and effectiveness of nighttime ventilation. As such, a significant challenge to building design is the realization of both healthy indoor environmental conditions and high levels of ventilation efficacy while simultaneously achieving environmental objectives. In this study, roof skylights were equipped with intelligent control systems to reduce the building's energy consumption using the principles of natural ventilation. This natural ventilation system reduces our reliance on air conditioning systems for building ventilation and significantly improves the comfort of indoor environments.

\subsection{Problem analysis}

This study was conducted in Taiwan, which has a subtropical island-type climate. Buildings capable of natural ventilation are in great demand because of the high temperatures and humidity levels during the summer. However, conventional, terraced houses are generally constructed in a sealed manner. This leads to ventilation losses between sealed spaces and environmental issues, such as a poor indoor air quality and stagnant spaces. The indiscriminate use of air conditioning as a way of forcefully improving building ventilation has led to additional energy consumption and economic waste (Fig. 1).

Our system resembles heat recovery ventilators (HRVs) in that it uses air circulation devices to improve the comfort of indoor air environments and represents a solution for reducing energy consumption and air-conditioning load. HRVs use a balanced method of ventilation, where inflows of air are balanced by outflows and where heat is recycled from the air discharged through the pipes. This reduces the inflow of cold air during winter and the need for heating, referred to as the counter-flow heat exchange mode of ventilation. ${ }^{(31)}$ Our system differs from an HRV in that it is a wind-tracking and wind-guiding system, actively encouraging fresh air indoors. This system is able to adapt to seasonal airflow characteristics because it automatically opens and closes its shutters according to the current speed and direction of the wind. While HRV systems are most suitable for winter, our system is most effective during spring and

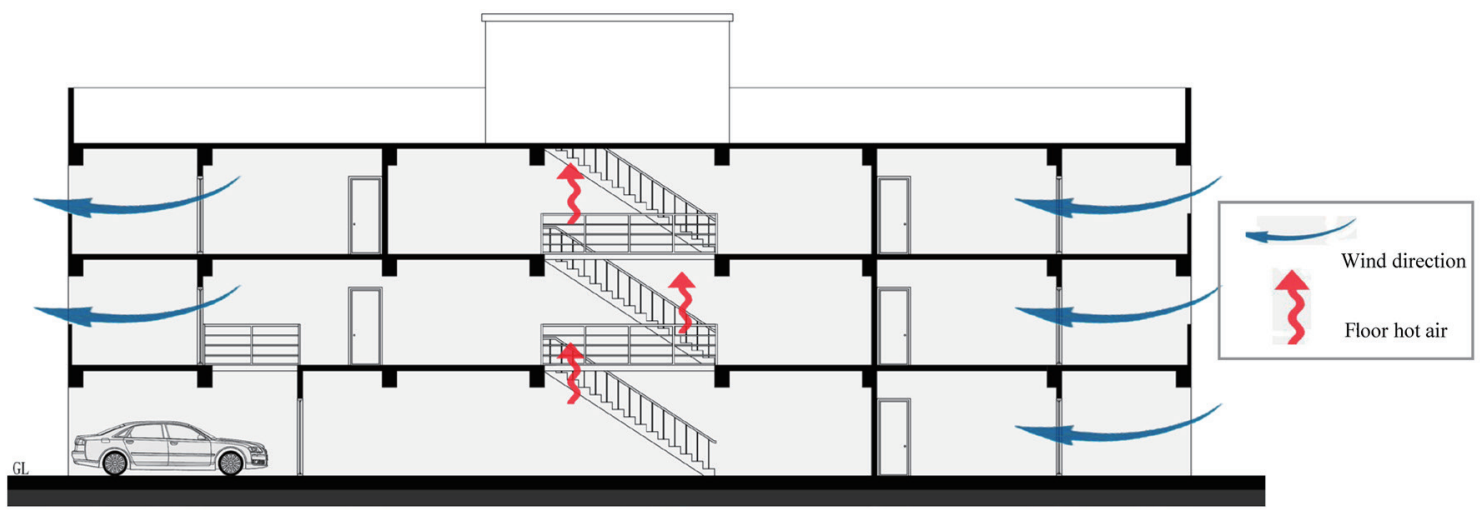

Fig. 1. (Color) Ventilation diagram of a three-story house. 
autumn. Although their functions are slightly different, these ventilation systems can be used in tandem.

\subsection{Conceptual design}

The design of the proposed ventilation system involves a conceptual development, as well as system prototyping. The iterative optimization, development, and evolution of this design led to several design iterations. A prototype was used to simulate the effects of different wind directions on the ventilation efficacy of the final design. The explorations performed during each iteration and the issues uncovered through this process are described below.

- First design iteration: fresh air is guided indoors using wind-guiding plates. The weakness of this system was that changes in wind direction altered the direction of the airflow [Fig. 2(a)].

- Second design iteration: rods were added to allow the wind boards to open upward, which brought in larger quantities of fresh air from the outside [Fig. 2(b)].

- Third design iteration: trusses were added to support the wind boards and rods, increasing the stability of wind-guiding equipment. However, the unidirectionality of this system led to a waste of fresh airflow guided into the structure [Fig. 2(c)].

- Fourth design iteration: improvements to the angles and positions of airflow-guiding plates led to the effective control of fresh airflow guided into the building (Fig. 3).

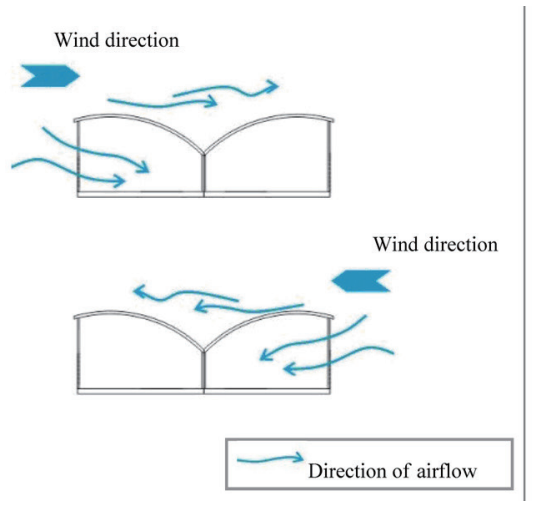

(a)

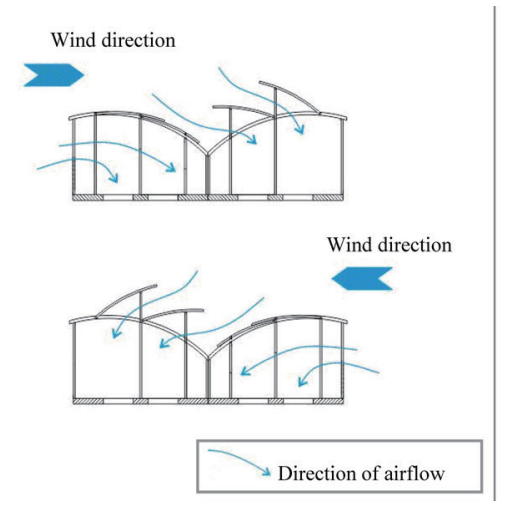

(b)

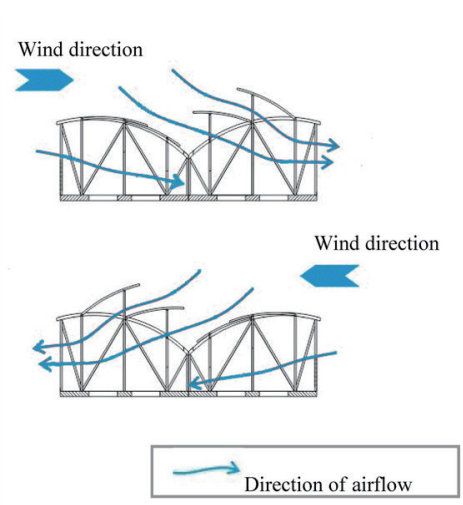

(c)

Fig. 2. (Color) (a) First design iteration, (b) second design iteration, and (c) third design iteration.

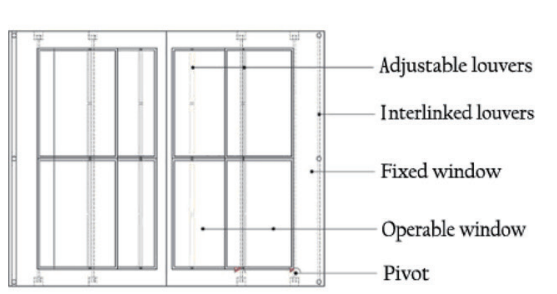

(a)

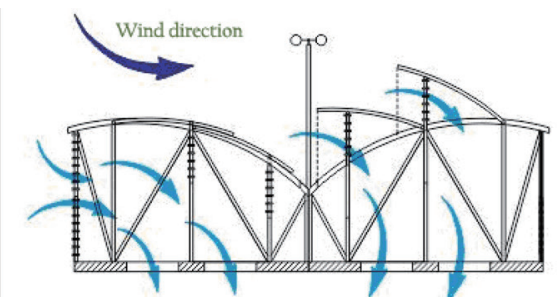

(b)

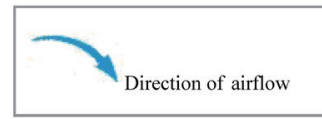

Fig. 3. (Color) Fourth design iteration. (a) Adjustable louvers and interlinked louvers and (b) wind-tracking system. 
- Fifth design iteration: wireless, integrated control equipment, environmental sensors, remote control equipment, and decision-making equipment were added to the system, resulting in optimal system operation (Fig. 4).

The design shown in Fig. 4 includes the following three major systems: a wind-tracking system, responsible for sensing the direction of the wind, tracking the quantity of airflow being guided indoors by the interlinked wind-guiding plates, and thereby regulating the indoor temperatures; an adjustable louver system, responsible for the operation of louvers (closing and opening), thus determining the direction of the wind that will be directed indoors; an interlinked louver system using the interlinking mechanism of the aforementioned adjustable louver system to control the direction of the airflow guided into the system.

\section{System Implementation}

\subsection{Implementation of the airflow-guiding structural system}

The devices used in this system function through the principles of thermal buoyancy and gravity. The system's structure includes both environmental sensors that measure temperature and humidity, and a windmill anemometer that measures wind speed and direction in an outdoor environment. Wind speed and direction, along with other environmental data, are transmitted to the control system database for processing. On the basis of the results of the system analysis, the rotational controller adjusts the direction and angle of the skylight openings, and a set of electrically powered rods open the skylights to allow airflow indoors. The angle of the openings may change among 30,60, and $90^{\circ}$, depending on the detected bearing of the wind. If the wind speed cannot be measured, the system activates the interlinked louvers located on both sides of the skylights, which vent hot air outward, improving indoor air quality and comfort. This system is particularly effective for nighttime ventilation during spring and autumn. By reducing the frequency of air-conditioning usage, energy consumption will be reduced. Through this system, the removal of hot air from the indoor environment allows air quality to be maintained and temperature to decrease. Figure 5 shows the windtracking ventilation system developed in this study based on the above core principles.

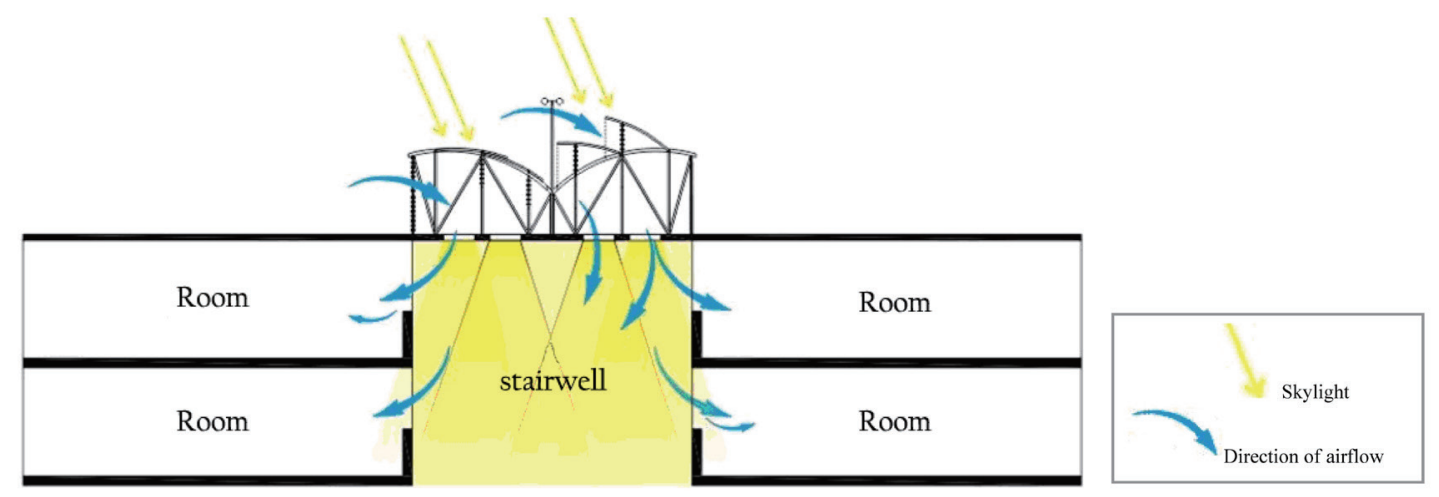

Fig. 4. (Color) Fifth design iteration. 


\subsection{Implementation of the control system}

This system consists of an autonomous control module and a machine control mechanism. After receiving data from the sensor network, the autonomous control module uses the mechanical control mechanism to perform the control operations, for example, the opening, closing, and adjustment of louvers. The autonomous control module includes a number of environmental sensors measuring temperature, humidity, wind speed, and wind direction. These sensors act as the sensory functions of the ventilation system. The autonomous control module integrates devices of this system through wireless network and communication technologies, and transfers the information acquired by each sensor to its decision-making module (Fig. 6).

After the decision-making module has completed its calculations based on the current environmental database, historical database, and judgment-rule base, the decision signal is transmitted to the machine control mechanism through remote control devices. The airflowguiding and airflow-venting equipment are then adjusted and controlled using the machine control mechanism. The architecture of the control system is shown in Fig. 7. On the basis of their own preferences, users may additionally use a smartphone app to set the size and angle of the opening in the skylight. The user interface of the smartphone app that accompanies this system displays (1) the opening size, angle, and state of control of the rooftop skylights; (2) the on or off state of the fan and its controls; and (3) information such as the rotation angle of the wind, wind speed, temperature, and humidity.

This system's prototype was implemented using Arduino Uno circuit boards, where a Bluetooth data-transfer module and servo motors were installed. The control components

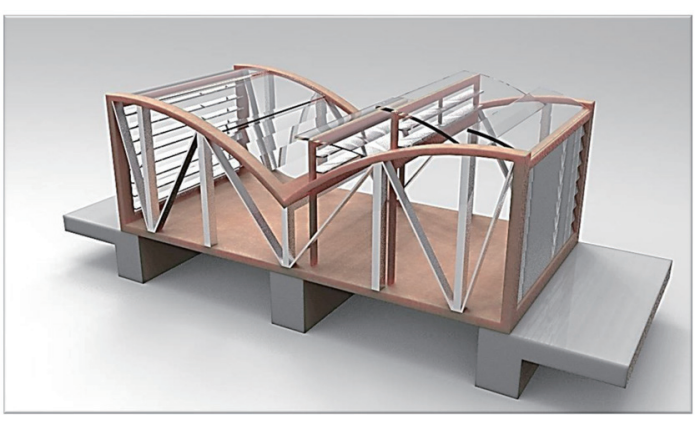

Fig. 5. (Color) Computer-generated stereogram of the wind-tracking ventilation structure.

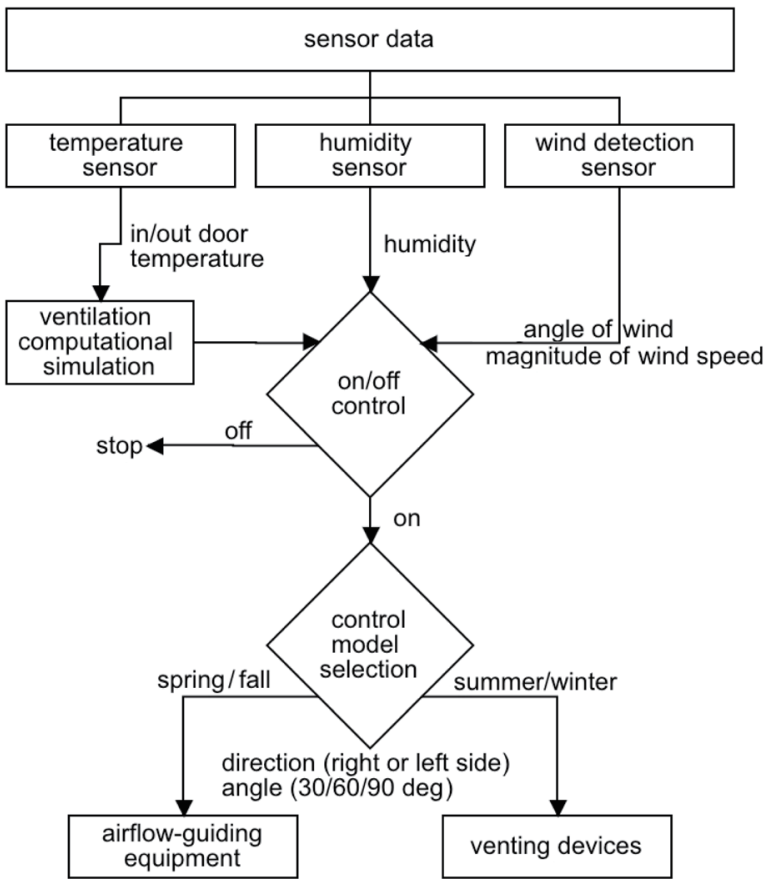

Fig. 6. Data processing for the decision-making module. 


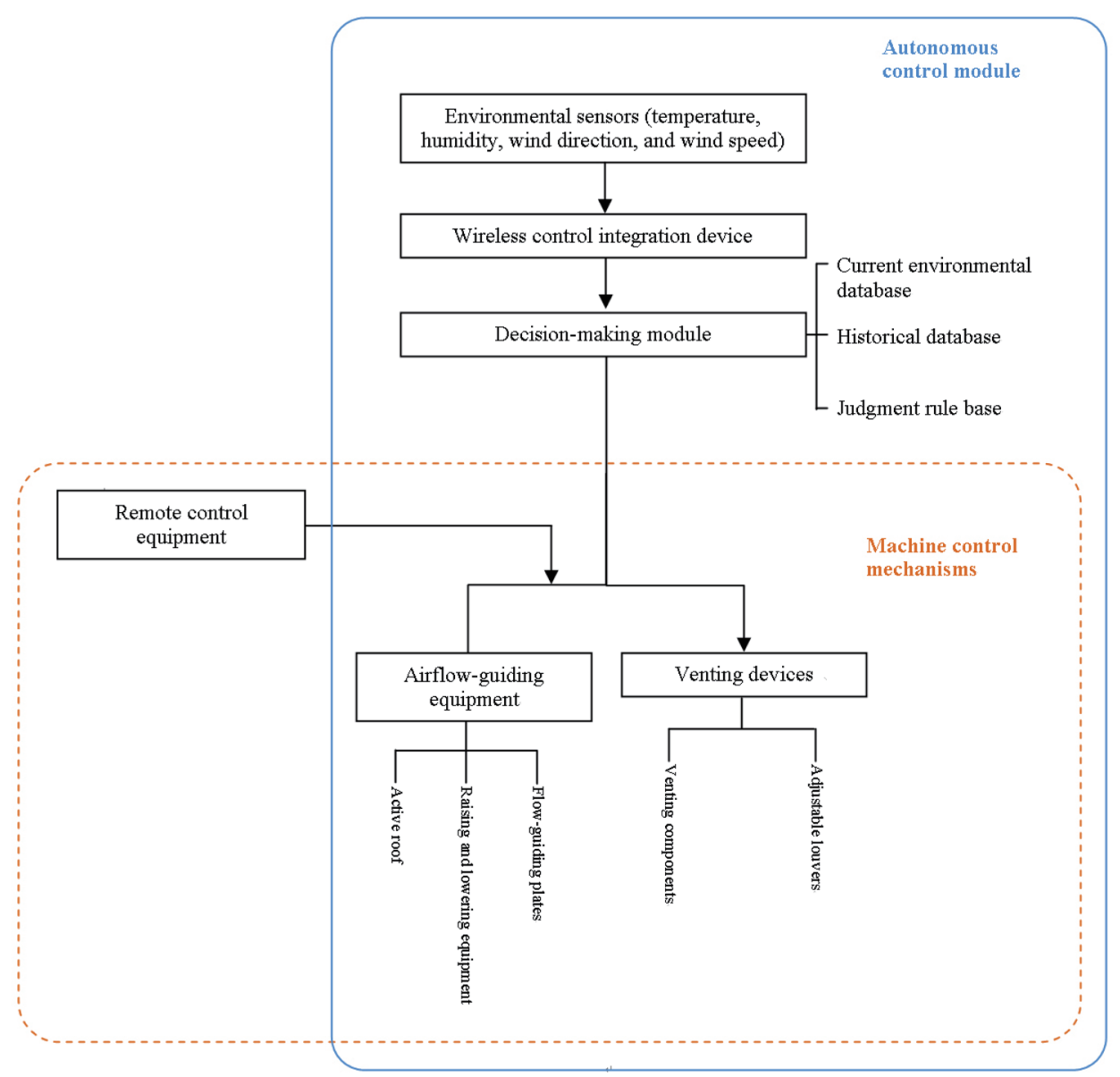

Fig. 7. (Color) System integration flowchart.

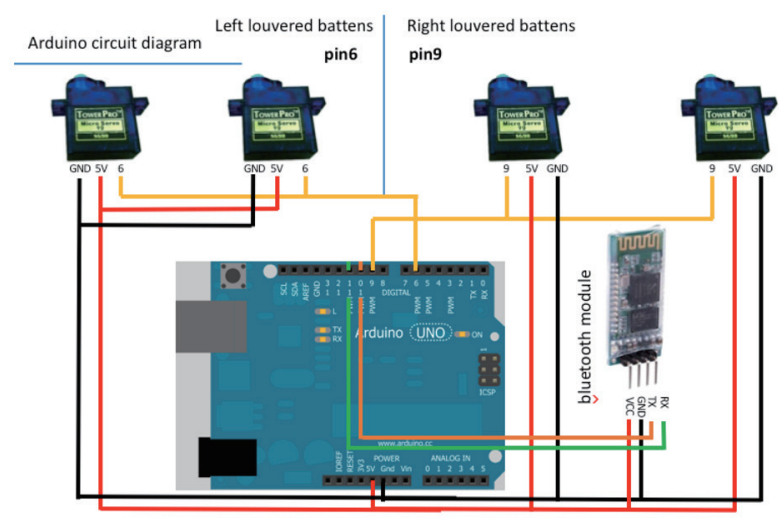

(a)

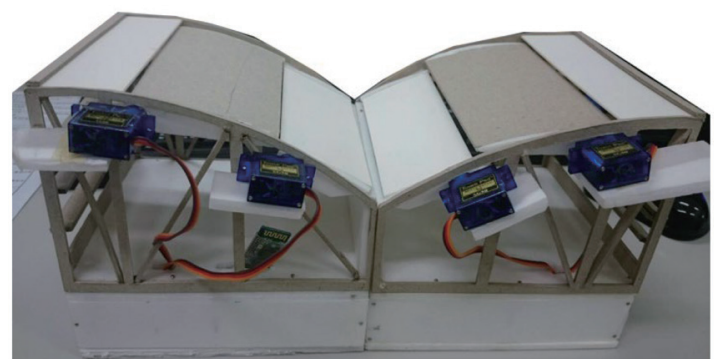

(b)

Fig. 8. (Color) (a) Implementation of the prototype control system and (b) appearance of the implemented prototype control system.

include an Arduino Uno circuit board, four servo motors, a Bluetooth communications module, and a Dupont line. The servo motors were used to control the louvered windows, while the Dupont line was used to facilitate communication between the modules. The circuit architecture of the prototype control system is shown in Fig. 8. 
We used the Massachusetts Institute of Technology (MIT) APP Inventor 2 platform to develop an Android app for the display and interactive control of the system. ${ }^{(32)}$ This allows the user to conveniently display (monitor) the state of the system and control managed devices without being restricted by time or space. Figure 9 shows the visual interface of App Inventor 2 and the app code. Figure 10 presents the interface and functions of the developed Android app.

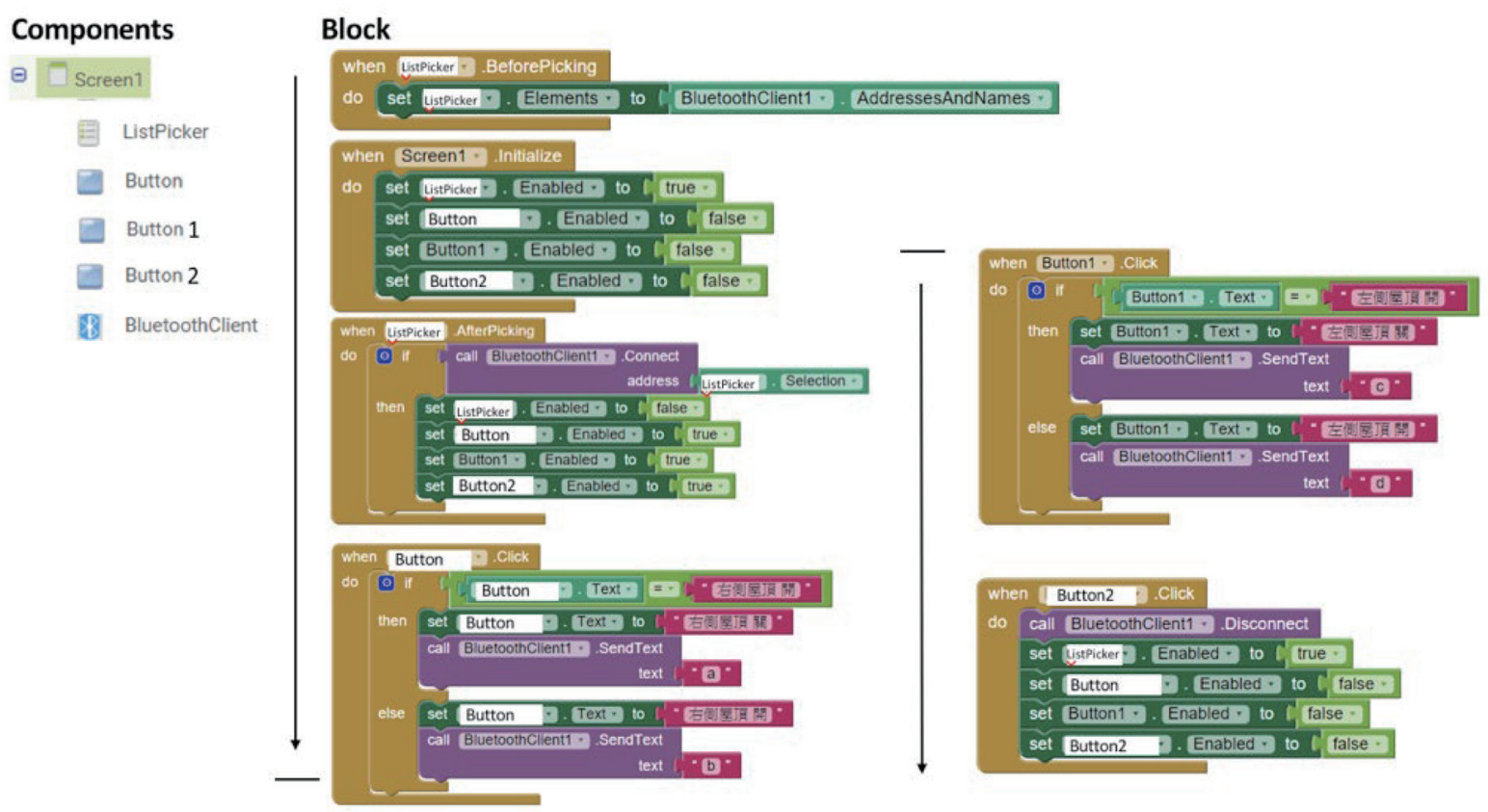

Fig. 9. (Color) MIT APP Inventor 2 platform used to construct the Android control app.

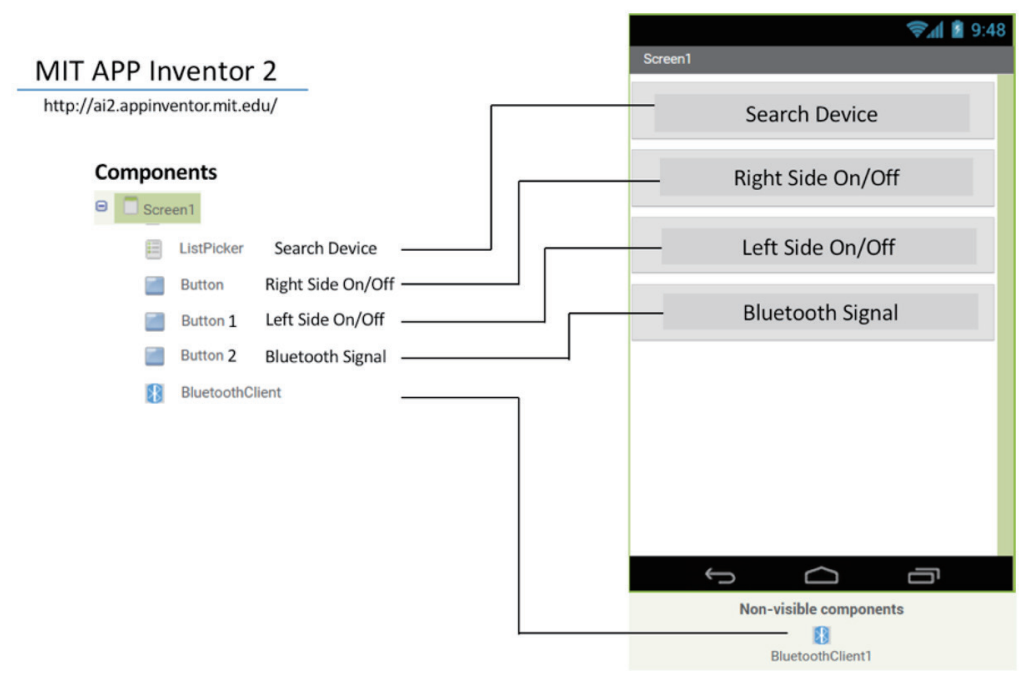

Fig. 10. (Color) Prototype interface of the Android control app. 


\section{Conclusions}

On the basis of advances in information and network technologies, we developed a novel ventilation system capable of tracking wind direction using wireless control technologies and sensory capabilities. The main strengths of this system include its ability to actively guide airflow into a building without the need for a passive energy-saving system and its easy installation onto a building roof. Furthermore, the IoT and sensor technologies used in this ventilation system allow remote control through computers and mobile apps, and the autonomous sensing and regulation of comfort levels within an indoor environment. The system operations run when the user is absent from the building and are unrestricted by time. As a result, the system is both convenient and in line with modern pursuits of health, energy efficiency, and comfortable living environments.

Natural ventilation is an extremely important aspect of building design because it is concerned with the maintenance of comfortable temperature, humidity level, and air quality within the building. In the past, building designers could only use their knowledge of buildings and environmental control to propose ventilation solutions that were based on passive designs. The regulation of temperature and humidity was achieved by adjusting building openings and the design of the building structures and spaces based on wind force and airflow assessments.

A number of ventilation systems were previously proposed for use in air-circulating devices to achieve natural ventilation. Most of these systems share certain similarities, such as the extensive use of transparent materials and the ease of installation and maintenance. Furthermore, these systems are usually passive building-integrated systems that help improve the comfort of indoor environments and reduce energy consumption. The wirelessly controlled wind-tracking ventilation system developed in the present study improves all characteristics of previous air-circulating systems and integrates wireless networks and sensors. As the system can be controlled remotely and monitored using a mobile device, its users can monitor the environmental state of their home or building at any point in time, allowing them to obtain an intelligent and comfortable living environment. This is a necessity for modern living, in light of global trends toward mobility. The prototype proposed in this study was implemented by a Bluetooth protocol. Bluetooth's communication distance is $10 \mathrm{~m}$ and its transmission rate is $3 \mathrm{Mbps}$. We suggest that future studies use $3 \mathrm{G}$ or ZigBee long-distance communication protocols as a means of implementing the system in real cases.

This system can be used to resolve air quality and ventilation issues of low and lengthy buildings. In this study, we constructed a 1:20 scale model to study and predict the effectiveness of the proposed system in ventilating buildings and other indoor environments. Future research is needed to validate the indoor ventilation capabilities of our system through wind-tunnel experiments, CFD calculations, and numerical analyses via computer-assisted architectural design software. Furthermore, the required ventilation rate in indoor spaces needs to be determined, and energy simulations (Energy Plus) and cost optimizations need to be carried out to apply energy-saving optimizations to energy-saving designs. Building a physical prototype makes it easier to visualize our investigations. It also enables the system's implementation in actual buildings for field trials, helping to ascertain its effectiveness in saving energy and improving the comfort of indoor environments. 


\section{Acknowledgments}

The authors would like to acknowledge the financial support provided by the Ministry of Science and Technology (MOST), Taiwan, under project number MOST 106-2511-S-163-001. The results of this study also led to the issuing of two patents by the Taiwanese government: The Wind Tracking Ventilation system of Architecture Patent (Patent Number: New Type M501542) and The Wind Tracking Ventilation System of Architecture with IoT (Patent Number: Invention No. I570366).

\section{References}

1 F. Allard : Natural Ventilation in Buildings: A Design Handbook, M. Santamouris, Ed. (Earthscan Publications Ltd., London, 1998).

2 C.-R. Chu and B.-F. Chiang: Build. Environ. 80 (2014) 150. https://doi.org/10.1016/j.buildenv.2014.05.017

3 G. Cao, H. Awbi, R. Yao, Y. Fan, K. Sirén, R. Kosonen, and J. Zhang: Build. Environ. 73 (2014) 171. https:// doi.org/10.1016/j.buildenv.2013.12.009

4 P. F. Linden: Annu. Rev. Fluid Mech. 31 (1999) 201. https://doi.org/10.1146/annurev.fluid.31.1.201

5 X. Yang, K. Zhong, H. Zhu, and Y. Kang: Build. Environ. 77 (2014) 29. https://doi.org/10.1016/j.buildenv.2014. 03.013

6 Y. Jiang, D. Alexander, H. Jenkins, R. Arthur, and Q. Chen: J. Wind Eng. Ind. Aerodyn. 91 (2003) 331. https:// doi.org/10.1016/S0167-6105(02)00380-X

7 Y. Li and A. Delsante: Build. Environ. 36 (2001) 59. https://doi.org/10.1016/S0360-1323(99)00070-0

8 M. Lin, J. Hang, Y. Li, Z. Luo, and M. Sandberg: Build. Environ. 79 (2014) 152. https://doi.org/10.1016/ j.buildenv.2014.05.008

9 A. R. Dehghani-sanij, M. Soltani, and K. Raahemifar: Renewable Sustainable Energy Rev. 42 (2015) 182. https://doi.org/10.1016/j.rser.2014.10.018

10 A. Rackes and M. S. Waring: Energy Build. 75 (2014) 272. https://doi.org/10.1016/j.enbuild.2014.02.024

11 Y. Zhang, H. Cui, W. Tang, G. Sang, and H. Wu: Energies 10 (2017) 1214. https://doi.org/10.3390/en10081214

12 Y. Wang, Y. Liu, D. Wang,and J. Liu: Energy Build. 80 (2014) 366. https://doi.org/10.1016/j.enbuild.2014.05.051

13 R. Ramponi, A. Angelotti, and B. Blocken: Appl. Energy 123 (2014) 185. https://doi.org/10.1016/ j.apenergy.2014.02.041

14 A. A. Jamaludin, H. Hussein, A. R. M. Ariffin, and N. Keumala: Energy Build. 72 (2014) 340. https://doi. org/10.1016/j.enbuild.2013.12.050

15 R. Ramponi, I. Gaetani, and A. Angelotti: Energy Build. 78 (2014) 25. https://doi.org/10.1016/ j.enbuild.2014.04.001

16 I. Oropeza-Perez and P. A. Østergaard: Appl. Energy 130 (2014) 20. https://doi.org/10.1016/ j.apenergy.2014.05.035

17 H. Y. Kim and H. J. Kang: Energies 9 (2016) 181. https://doi.org/10.3390/en9030181

18 J. K. Calautit and B. R. Hughes: Build. Environ. 80 (2014) 71. https://doi.org/10.1016/j.buildenv.2014.05.022

19 A. Belleri, R. Lollini, and S. M. Dutton: Build. Environ. 81 (2014) 123. https://doi.org/10.1016/ j.buildenv.2014.06.009

20 D. Kolokotsa: Energy Build. 116 (2016) 703. https://doi.org/10.1016/j.enbuild.2015.12.033

21 S. Zheng, X. Xiong, J. Vause, and J. Liu: Int. J. Sustainable Dev. World Ecol. 20 (2013) 254. https://doi.org/10.1 080/13504509.2013.779616

22 K. Akkaya, I. Guvenc, R. Aygun, N. Pala, and A. Kadri: 2015 IEEE Wireless Communications and Networking Conf. Workshops (IEEE,2015) 58. https://doi.org/10.1109/WCNCW.2015.7122529

23 M. Feldmeier and J. A. Paradiso: IEEE Internet Things (2010) 1. https://doi.org/10.1109/IOT.2010.5678444

24 M. V. Moreno, M. A. Zamora, and A. F. Skarmeta: Int. J. Web Grid Serv. 11 (2015) 78. https://doi.org/10.1504/ IJWGS.2015.067157

25 A. Aijaz and A. H. Aghvami: IEEE Internet of Things 2 (2015) 103. https://doi.org/10.1109/JIOT.2015.2390775

26 A. Sheth: IEEE Intell. Syst. 31 (2016) 108. https://doi.org/10.1109/MIS.2016.34

27 R. Albatici, F. Passerini, and J. Pfafferott : Energies 9 (2016) 365. https://doi.org/10.3390/en9050365

28 M. I. Iqbal, R. Himmler, and S. H. Gheewala: Energy Build. 134 (2017) 295. https://doi.org/10.1016/ j.enbuild.2016.11.002 
29 S. Feng, P. Setoodeh, and S. Haykin: IEEE Commun. Mag. 55 (2017) 34. https://doi.org/10.1109/ MCOM.2017.1600682CM

30 B. L. R. Stojkoska and K. V. Trivodaliev: J. Cleaner Prod. 140 (2017) 1454. https://doi.org/10.1016/ j.jclepro.2016.10.006

31 J.-H. Kim, J.-G. Ahn, and J.-T. Kim: Energies 9 (2016) 728. https://doi.org/10.3390/en9090728

32 MIT Center for Mobile Learning, App Inventor 2 home page: http://appinventor.mit.edu (accessed February 2014).

\section{About the Authors}

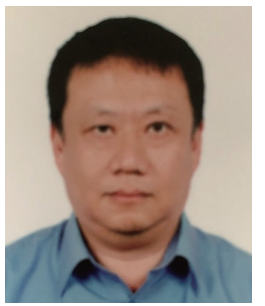

Yun-Wu Wu received his master's degree in architecture from University of Illinois at Urbana-Champaign, U.S.A., in 1982. He received his doctoral degree in civil engineering from National Taiwan University of Science and Technology, Taiwan, in 2006. He is a professor in the Department of Architecture, China University of Technology, Taiwan. His research interests include engineering education, creativity, energy-saving technology, e-learning, and the application of Internet of Things (IoT) in building technology and property management. (davidwu@cute.edu.tw)

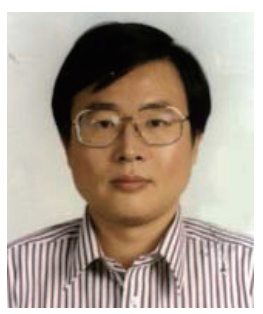

Jin-Lian Lee received his M.S. degree from the Department of Civil Engineering, Tamkang University, in 1983. His profession is related to geotechnical engineering, structural engineering, and building engineering. He has been a lecturer in the Department of Architecture, China University of Technology, Taiwan, since 1992. (g1200832@hotmail.com)

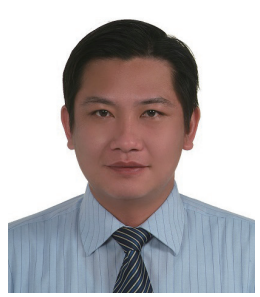

Wei-Chung Kuo received his Bachelor of Architecture degree from Feng Chia University, Taiwan, in 1995. In 2010, he obtained his M.Arch. from National Taipei University of Technology, where he is currently pursuing his doctoral degree and specializing in architecture design and physics. (t105859012@ntut.edu.tw)

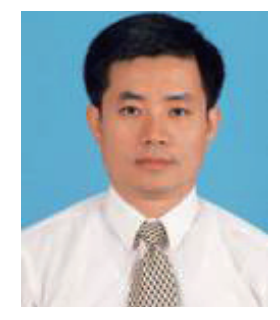

Ding-Chin Chou received his M.D. from the School of Architecture, University of Cheng Kung, Tainan, in 1983 and his Ph.D. from the School of Architecture, Southeast University, China, in 1994. His research areas and interests are related to energy saving for architecture, lighting and the visual environment, and green buildings. He works as a professor in Graduate Institute of Architecture and Urban Design, Architecture Department, National Taipei University of Technology. (dcchou@ntut.edu.tw) 


\section{Appendix A}

The results of the simulation were filmed and posted on YouTube. The video can be viewed at https://goo.gl/nU6q84 or by scanning the QR code below (Fig. A1).

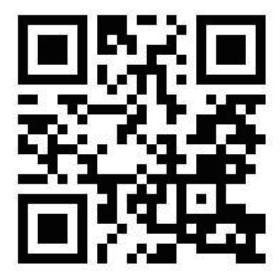

Fig. A1. Video of the simulation of the wind-tracking ventilation system.

\section{Appendix B}

The control module programs were coded using the Arduino language, as shown in Fig. B1. The source code is shown on the left and the comments are shown on the right.

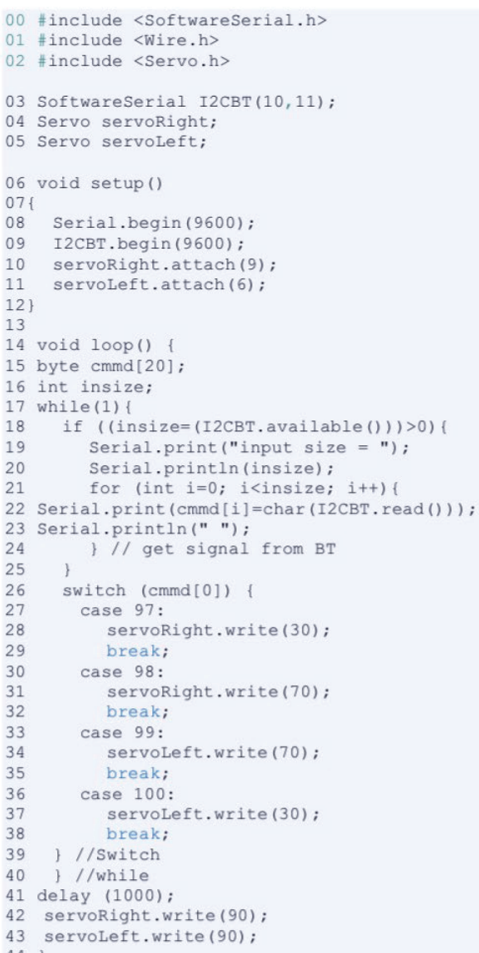

01: // Includes three libraries, i.e., SoftwareSerial, Wire, and Servo

03: // Defines PIN10 and PIN11 as the feet for RX and TX, respectively

04: // Defines the number of servos

09: // Initial baud rate of Arduino: 9600

10: // Right servo motor PIN9

11: // Left servo motor PIN6

18: // Reads Bluetooth signals

26: // Reads the first character

27: // 97 is the ASCII code of "a"

28: // The initial rotational position of the right servo motor is $30^{\circ}$

30: // 98 is the ASCII code of "b"

31: // The final rotational position of the right servo motor is $70^{\circ}$

33: // 99 is the ASCII code of "c"

34: // The final rotational position of the left servo motor is $70^{\circ}$

36: // 100 is the ASCII code of " $d$ "

37: // The initial rotational position of the left servo motor is $30^{\circ}$

Fig. B1. (Color) Arduino code used to construct the control system. 